\title{
Health promotion in care organizations as material-discursive practices
}

\section{Segercrantz, Beata}

2021-02-23

Segercrantz , B , Tuori , A \& Niemistö , C 2021 , ' Health promotion in care organizations as material-discursive practices ', Qualitative Research in Organizations and Management: An International Journal , vol. 16 , no. 1 , pp. 170-190 . https://doi.org/10.1108/QROM-09-2019-1826

http://hdl.handle.net/10138/338990

https://doi.org/10.1108/QROM-09-2019-1826

cc_by_nc

acceptedVersion

Downloaded from Helda, University of Helsinki institutional repository.

This is an electronic reprint of the original article.

This reprint may differ from the original in pagination and typographic detail.

Please cite the original version. 


\section{Health promotion in care organizations as material- discursive practices}

\begin{tabular}{|r|l|}
\hline Journal: & Qualitative Research in Organizations and Management \\
\hline Manuscript ID & QROM-09-2019-1826.R3 \\
\hline Manuscript Type: & Original Article \\
\hline Keywords: & Health promotion, Illness, Discourse, Materiality, Body, Care work \\
\hline \multicolumn{2}{|l}{} \\
\end{tabular}

SCHOLARONE $^{\text {m }}$
Manuscripts 


\title{
Health promotion in care organizations as material-discursive practices
}

\begin{abstract}
Purpose - Drawing on a performative ontology, this article extends the literature on health promotion in organizations by exploring how health promotion is performed in care work. The focus of the study is on health promotion in a context of illness and/or decline, which form the core of the studied organizational activities. The paper addresses the following question: how do care workers working in elderly care and mental health care organizations accomplish health promotion in the context of illness and/or decline?
\end{abstract}

Design/methodology/approach - The article develops a performative approach and analyses material-discursive practices in health promoting care work. The empirical material includes 36 semi-structured interviews with care workers, observations and organizational documents.

Findings - Two central material-discursive health promoting practices in care work are identified: confirming that celebrates service users as residents and the organizations as a home, and balancing at the limits of health promotion. The practices of balancing make the limitations of health promotion discernible and involve reconciling health promotion with that which does not neatly fit into it (illness, unachievable care aims, the institution and certain organizing). In sum, the study shows how health promotion can structure processes in care homes where illness and decline often are particularly palpable.

Originality/value - The paper explores health promotion in a context rarely explored in organization studies. Previous organization studies have to some extent explored health promotion and care work, but typically separately. Further, the few studies that have adopted a performative approach to material-discursive practices in the context of care work have typically primarily 
focused on IT. We extend previous organization studies literature by producing new insights: (1) from an important organizational context of health promotion and (2) of under-researched entanglements of human and non-human actors in care work providing a performative theory of reconciling organizational tensions.

Keywords - Health promotion, Illness, Material-Discursive Practices, Performativity, Care work, Organizing, Body, Space, Object

Paper type - Research paper 


\section{Introduction}

The interest in health promotion has increased dramatically in politics, policy, organizations and care across the world and sectors during the last decades (Bache and Reardon, 2016; Cederstöm and Spicer, 2015; Dale and Burrell, 2014). Health promotion can be defined as support to the individual to engage in actions that enhance her/his health. The concept rests on the idea that living conditions and behavior may significantly influence the individual's health (Crossley, 2000), the individual has an obligation to strive to be healthy (McKinlay and McVittie, 2009) and particular behaviors can be promoted through governmental and organizational initiatives and communication (Bache and Reardon, 2016; Fineman, 2014; Jones and Watson, 2009). It has been argued that this idea, emphasizing the optimizing of health, has been celebrated in contemporary society and organizations to the extent that health promotion has become ideological (Cederstöm and Spicer, 2015; Crossley, 2000; McKinlay and McVittie, 2009).

Health studies typically attempt '(1) to predict health- and illness-related behavior through the development and testing of theories and (2) to control, manage or change such behavior through the application of such theories' (Crossley, 2000, p. 2). Less attention has, however, been drawn to improving health care services (Chamberlain and Murray, 2009). Whereas health promotion can be examined within various care services and organizational contexts, an interesting context for studying this phenomenon is care organizations. Care organizations, in particular those that provide residential care, can be seen as arenas where health and illness are particularly central in everyday practices and organizing. Residential care can be carried out on the basis of different logics or ideologies, such as, cost-efficiency, illness, decline and/or health. In this study, we examine care organizations that celebrate the health approach and ask: How do care workers 
working in elderly care and mental health care organizations accomplish health promotion in the context of illness and/or decline? We do so in order to illuminate how health promotion is accomplished in a context where not only health and recovery, but also illness and/or decline constitute the core of the organizational activities. Within this organizational context, health promotion is often translated into rehabilitating care and a desire to create institutional living that resembles home-like environments.

Performative and material-discursive perspectives have gained growing attention in organization studies as a response to a concern that organizational language based analyses have not given sufficient attention to the material (for example, Fotaki et al., 2014; Gond et al., 2016; Hardy and Thomas, 2015; Orlikowski and Scott, 2015; Phillips and Oswick, 2012; Putnam, 2015; see also Gherardi et al., 2013; Lindberg, 2014). Therefore, we adopt a performative perspective with a focus on material-discursive practices (Barad, 2003; 2007; Orlikowski and Scott, 2015) rather than exploring merely discourses of health promotion. We do so in order to account for how materiality and meanings are central in health promoting care work, that is, in a context in which both the material and discourses of health and illness are very palpable. Further, instead of exploring the relationship between the discursive and the material, for example, how discourses of health promotion and materialities of illness are interrelated, we examine how materiality and discourse are entangled and constitutive of health promotion. This means that we do not approach matter and meaning as separate interacting entities, the discursive as shaped by materiality or vice versa. Instead, we approach matter and meaning as continuously and dynamically produced in materialdiscursive practices (Barad, 2007; Orlikowski and Scott, 2015). This helps us to extend organizational studies of health promotion by examining and theorizing health promotion as 
material-discursive practices; practices that are constitutive of (care) work and thus performative. More specifically, we examine how health promotion is enacted and through this process structures care in particular ways, but consequently simultaneously excludes alternatives and other conditions of possibilities (Hultin and Introna, 2019; Scott and Orlikowski, 2014). To do so, we analyse 36 interviews from Finnish care organizations offering residential care: an organization for mental health care and drug rehabilitation as well as an organization providing elderly care.

\section{Health promotion in (care) work}

Health promotion is a multi-disciplinary research field. Health promotion in organizations has been examined, for example, at the level of ideology and power (for example, Cederstöm and Spicer, 2015; Dale and Burrell, 2014; Lupton, 1995; Thanem, 2009), the organization and/or the individual (Holmqvist, 2009; Nielsen, 2013), leadership (Thanem, 2013), and resistance (James and Zoller, 2018). Typically, the focus has been on enhancing employee health and well-being. In addition, employee health has been examined within the workplace, as connected to the private life and/or as a matter of work-life balance (for example, Maravelias, 2009). Some studies highlight that the promotion of employee health or well-being has a value in itself while others also have connected health to cost effectiveness, and organizational and state interests (Dale and Burrell, 2014; Lupton, 1995). This broad body of literature hence examines how health promotion is entangled in various ways with political, economic, ideological and organizational interests (Crossley, 2000; Dale and Burrell, 2014; Lupton, 1995).

The dominating approaches to health promotion in organizations have been problematized, although few would deny the importance and value of health in organizations. For example, 
Cederstöm and Spicer (2015) discuss how wellness has become a moral imperative and problematize this transformation by highlighting traps of health promotion. They argue that an ideological search for health and wellness may be counter-productive and have various undesirable effects. Likewise, Dale and Burrell (2014) argue that an organizational 'wellness movement' has emerged. They discuss how wellness is inseparable from its necessary Other, unwellness, although the wellness movement tend to prioritize wellness. In doing so organizations often disregard or silence the fact that unwellness may be required for meeting organizational profit goals.

In both the dominating and critical organizational literature of health there have been only limited attention drawn to occupations and professionals who are not the primary targets of health promotion, but rather the subjects involved in the implementation of health promotion in everyday organizational practices (for exceptions, see, Meldgaard Hansen and Kamp, 2018; Nyström et al., 2013). For example, care work has been studied from various perspectives in organization studies (see, for example, Cohen and Wolkowitz, 2018; Munro and Randall, 2007; Yakhlef and Essén, 2013), but typically not from the perspective of health promotion implementation even though this type a work foremost focuses on health, illness, decline and recovery. We therefore intend to address this shortcoming in our study.

Even though the concept salutogenesis is not very broadly used (Eriksson and Lindström, 2006) in organization studies it captures well health promoting care work. The concept of salutogenesis was introduced by Antonovsky (1979) and refers to 'the study of the origins and creation of health' and contributes a method to enhance health and well-being (Becker et al., 2015, p. 222). More specifically, salutogenesis differs from pathogenesis, which focuses on illness, disease and decline 
as well as methods to avoid, manage, reduce and/or cure illness (Torrès and Thurik, 2019). Salutogenesis does therefore not focus on decreasing disease, but instead takes health promotion as its main concern (Becker and Rhynders, 2013). Chrysikou et al. $(2018$, p. 6) argue that the objective is to 'support staff, carers and patients by decreasing the amount of effort needed to overcome stressful situations'. The role of salutogenic strategies is hence to support health professionals to promote 'positive health enhancement' by drawing attention to desired outcomes and effective paths to achieving health (Becker and Rhynders, 2013, p. 1).

Eriksson and Lindström (2006) emphasize that health promotion and prevention of disease can be seen as two sides of the same coin. Likewise, Chrysikou et al. (2018) argue that salutogenesis provides complimentary support to medical interventions. This is important in care organizations that wish to address problems that may arise from a prioritizing of one of the approaches (salutogenesis or pathogenesis) on the expense of the other. This takes us back to critical studies of health promotion in organizations. That is, although Dale and Burrell (2014) do not examine professionals engaged in implementing health promotion their emphasis on tensions between employee wellness and unwellness is relevant here. A one-sided focus on health in care organizations may at worst invite consent and prevent resistance to harmful health promotion efforts. This in turn may mask contradictory pressures and power relations. Likewise, a strong focus on health may imply that the other side (for example, illness) is silenced and vice versa. We address health promotion in care work with a particular focus on vulnerable groups, that is, older adults and persons with mental illnesses, who are not only dependent on health promoting care, but often also on prevention of disease and medical interventions. 


\section{Discourse and materiality in organization studies}

The linguistic turn in social sciences has in many ways enriched organization studies, but there has been a call for further developing these linguistic analyses (see, for example, Deetz, 2003; Hardy and Thomas, 2015; Orlikowski and Scott, 2015; Phillips and Oswick, 2012; Putnam, 2015). This call has been targeted, amongst a range of language based analyses, at discourse analysis. More specifically, although discourse analysis has brought novel and important issues on the research agendas in research fields, such as, health promotion, care work and organizing, over time scholars have raised a concern that many language analyses have become too preoccupied with language thus not giving satisfying attention to interconnections and entanglements beyond discourse (Barad, 2003; 2007). Barad (2003, p. 828) therefore promotes a 'rethinking of the notions of discursive practices and material phenomena and the relationship between them'.

\footnotetext{
Although materiality often has been neglected in organizational discourse analysis and theorizing (Fotaki et al., 2014), a growing body of work has highlighted or examined the relationship between the discursive and the material (Ashcraft et al., 2009; Hardy and Thomas, 2015; Hearn, 2014; Orlikowski and Scott, 2015; Putnam, 2015). In discursive-material studies there are various ways in which discourse scholars have approached materiality: some take a rather strong discursive position while others include to a greater extent the material in the analysis (Ashcraft et al., 2009; Phillips and Oswick, 2012).
}

Putnam (2015) identifies five different approaches to discourse and materiality in organization studies: foucauldian analysis, materiality and performativity, imbrication, plenum of agencies and the mangle. She identifies both similarities and differences between the approaches. A central 
similarity among all the approaches, with the exception of the 'materiality and performativity approach', is their treatment of discourse and materiality as 'distinct, interdependent, and/or simultaneously emergent' (Putnam, 2015, p. 712). More specifically, these approaches examine materiality and discourse as empirically distinct, but yet as mutually implicated. A challenge in approaching the material and the discursive as distinct in organizational analysis is the tendency to privilege discourse over materiality or vice versa (Putnam, 2015; Orlikowski and Scott, 2015). In these approaches, agency and intentionality are typically ascribed to the human actors above non-human actors. This, Hultin and Introna (2019) argue, is problematic if we are to move away from foregrounding speech-acts at the expense of various materialities in organizational analyses. For example, as mental illness, is both material and discursive, the materiality of the illness configures reality like discourse does and therefore, prioritizing discourse over materiality may limit our understanding of illness and care work.

To overcome the tendency to privilege either discourse or materiality some organization scholars have turned to the approach that Putnam (2015) names 'materiality and performativity' (see also Gond et al., 2016), an approach building foremost on Barad's theorizing (for example, Ford et al., 2017; Harding et al., 2017; Hultin and Introna, 2018). Whereas performativity can refer to a variety of perspectives and/or conceptualizations inspired by different theoretical turns, including linguistic, practice, process and material turns, (Gond et al., 2016), our understanding of performativity emphasizes practices, doings and actions and 'allows matter its due as an active participant in the world's becoming' (Barad, 2007, p. 136). Simultaneously, it highlights how discursive practices matters. 
We adopt this material-discursive performative approach in this study as it allows us to examine and theorize discursive practices and material phenomena in health promoting organizations without having to prioritize discourse above materiality, or human intentionality above the nonhuman. This seems important, in a context where materiality and discourses of health, illness and/or decline are entangled in the flow of practice and co-constitute care.

However, embracing both discourse and materiality without prioritizing one above the other is not enough in Barad's approach. The rejection of dualist thinking also invites a theorizing of materiality and discourse as inseparable (Barad, 2003; 2007; see also, for example, Orlikowski and Scott, 2015) by building on a relational and performative ontology foregrounding relations rather than entities. In our study of health promotion this implies that we do not understand, for example, service users, care workers, illness, decline and care homes as separate entities with inherent characteristics, which then interact, but as acquiring properties through their entanglements in an ever ongoing open-ended process of becoming (Scott and Orlikowski, 2014). In that sense relations are performative (subject and objects in care work are relationally enacted) turning the focal point of analysis to practices.

To understand how practice is theorized in this performative approach we need to dig deeper. In this engagement, it may be worth noting that Barad's approach, agential realism (Barad 2003; 2007), relies on a number of notions, notably, materiality, entanglement, relationality, performativity and practice. While some organization scholars have drawn on these notions selectively, Jones (2014) argues that great value may lie in giving attention to the notions more comprehensively in order to provide contributions that advance the foundations of the approach 
(Gond et al., 2016). We, therefore, adopt a relatively comprehensive approach to these concepts rather than selecting particular notions of focus.

First, the concepts entanglement and intra-action are crucial for Barad's theorizing of practice. Barad (2007, p. ix) argues, as already mentioned above, that '[t]o be entangled is not to be intertwined with another, as in the joining of separate entities, but to lack an independent, selfcontained existence'. This is why materiality is not understood in this approach as a separate, an individually articulated or static entity (Barad, 2007; Hultin and Mähring, 2017). Rather, different organizational realities are viewed as constituted through 'the entanglement of matter and meaning produced in practice within specific phenomena' (Scott and Orlikowski, 2014, p. 873), such as, bodies, spaces and objects in material-discursive practices within health promotion. More specifically, entanglements are theorized as, what Barad names, material-discursive intra-actions. Intra-action differs from the concept interaction, as interaction rests on the idea of exchange between distinct, separate discursive and material entities (Barad, 2007; Harding et al., 2017). Intra-actions imply that 'individuals emerge through and as part of their entangled intra-relating' (Barad, 2007, p. ix). It is 'through specific intra-actions that phenomena come to matter'; a phenomenon is entanglements of intra-acting agencies (Barad, 2007, p. 140).

Second, it is through intra-actions that distinctions and boundaries of a phenomenon are determined. As Scott and Orlikowski (2014, p. 878) explain '[t]hinking of entanglement in terms of intra-action focuses attention on the particular practices through which distinctions and boundaries ... are produced, stabilized and destabilized', for example, how distinctions of health and illness emerge. Intra-actions therefore enact what Barad calls agential cuts (Barad, 2003). Scott 
and Orlikowski (2014) explain that these are enactments that produce and fix distinctions. That is, an analysis of intra-actions enables us to examine how material-discursive practices enact health promotion in particular ways by including and excluding certain things and thus producing particular distinctions and boundaries or agential cuts (what is legitimate and what is not in care work). Here, materiality is seen as a process of materialization that configures and stabilizes health promotion over time (Barad, 2007).

Third, as the type of analysis we have sketched out above does not center at only the human but also the non-human we must also rethink agency. Barad (2007) claims that distinct, separate agencies do not precede; agencies are entangled and emerge in and through enactments and intraaction. Hence, from a performative perspective, matter is agentive and an active participant in practice (Barad, 2007; Ford et al., 2017). Likewise, agency is not located in individual actors, but flows constantly within and through practices that constitute conditions of possibility for subject positioning and action (Hultin and Introna, 2019). Barad argues that individuals materialize through and within entangled intra-relating and thus '[h]umans are neither pure cause nor pure effect but part of the world in its open-ended becoming' (Barad, 2007, p. 150). As Hultin and Introna (2019, p. 1362) argue, 'mundane material-discursive practices always and already condition (or govern) the possibilities within which all subject and object positionings become taken as meaningful ways to be and act'.

For the study of health promoting practices in organizations, we find analyzes of materialdiscursive practices promising. As mentioned earlier, there is a growing body of materialdiscursive studies in organization studies, but within this field only few have examined material- 
discursive practices (Gond et al., 2015) in social and health care. Gond et al. (2015) argue that organization scholars drawing on Barad typically examine IT (information technology) problems in organizations. Some of these studies have explored IT in social and health care. For example, Jones (2014) investigates the adoption of a computer based clinical information system in a hospital critical care unit showing how a transformation from paper to electronic records through material-discursive practices 'bring into play power relations, norms, and understandings (of experiences, of competencies, of medical knowledge) and evoke emotions (of fear, of interest, of relief)' (Jones, 2014, p. 915). Likewise, Polykarpou et al. (2018) explore practitioners' justification of health IT investments, Timmons et al. (2019) analyzes radio pagers implemented to prevent older adults' bedside falls in hospitals, while Introna et al. (2019) examines a computerized physician order entry system in a hospital context. Hultin and Mähring (2017) show how material-discursive analyses can be applied to analyzing digital and physical visualization boards. Further, Gherardi and Rodeschini (2016) study an organizational change from natural nutrition to artificial feeding or tube feeding in a nursing home for older adults highlighting collective and organizational ethics of care.

It could be argued, that the primary focus in performative studies, as the ones referred to above, is typically on problems, changes, implementation and use related to IT, digital and/or other technologies, yet without a neglect of other organizing objects in health care. Together these studies, hence, show the dynamics of the entanglement of materiality and discourse in practice and conditions of possibility specifically in the context of IT implementation/use in hospitals and care homes. Jensen and Muhr (2020) on the other hand draw in more detail attention to care workers. They explore performative identity regulation in home care where rehabilitation is celebrated 
above traditional nurturing. Jensen and Muhr (2020) illustrate the powerful material dimensions of identity regulation and embodied ideals amongst care workers.

With the exception of, for example, Jensen and Muhr (2020) few organization scholars have, however, explored material-discursive practices of care work without taking IT, digital and other technologies as their focal point, or focused on health promoting care work. We therefore address this shortcoming in organization studies from a performative perspective. We focus on how care workers accomplish health promotion in the context of illness and/or decline, taking into consideration various materialities, such as, bodies, objects and spaces without prioritizing IT above other organizing objects. This enables a more nuanced study of how health promotion is performed in material-discursive practices that configures care work. As Orlikowski and Scott (2015, p. 703) argue this provides opportunities to 'detailing how specific materializations of discourse make a difference in practice, and with what performative consequences'. In our study, this involves examining discursive materializations of care work; how care work is (re)configured in a context where health promotion efforts in organizations are increasing.

\section{Method}

\section{Context and Data}

We collected our data in Finland in 2014 and 2016. We selected two non-profit third sector organizations for the study: one in elderly care referred to here as EasyCare, and one in rehabilitation for people with mental illnesses and/or drug addictions, which we call Step-by-Step. EasyCare is a relatively large provider of various social and health care services (having nearly 1000 employees) and provides residential care for older adults in approximately 20 locations in 
Finland. The interviews in this case organization were conducted in four different residential care homes providing round-the-clock services for older adults, each consisting of two or more units (each unit providing a home for 10-20 older adults). Step-by-Step is a provider of rehabilitation services for persons with mental illnesses and addictions and provides residential care as well as supported independent housing. The organization employs approximately 60 employees. The interviews at Step-by-Step were conducted in a 24/7 residential care home.

We gained access through direct contact by phone and email followed by meetings with the management of the organizations. The management approved the research permits. The managers acquired about voluntary research participants amongst care workers. The interviews were carried out in the organizations' office spaces, where only the interviewee and the researcher were present. The interviews began by gaining informed consent from the participants to guarantee the interviewees confidentiality and anonymity. In the reporting pseudonyms are used for the organizations as well as the participants.

We conducted 25 interviews with 22 care workers and middle managers at EasyCare and 11 interviews with care workers and middle managers at Step-by-Step (as EasyCare was a larger organizations we were offered to do more interviews there). The interviews at EasyCare varied in length from 0,5-1,5 hours and were carried out in Finnish, Swedish and English while the interviews at Step-by-Step took approximately 1-1,5 hours and were all conducted in Finnish. All interviews were recorded and transcribed. The interviews covered a variety of topics around everyday care work, thus providing in-depth reflections around care practices, which would have been challenging to access through other types of data. The interviews therefore constitute a 
suitable and rich material for analyzing material-discursive practices of health promoting care work. Although the interviews constitute the main research material, during our visits to the units we also made some observations in the units to gain insight into the daily care practices (the observation were not conducted or documented in a systematic way, but rather worked as a way of contextualizing the interviews). A middle manager showed us around at the care homes and we made notes that described the spaces (what the spaces looked like). At EasyCare we gained access to spend time in the living room and observe the daily practices (how the care workers and older adults socialized and had lunch, as well as observed staff meetings, and how care workers documented care and changed shifts). We also had access to official documents in the studied organizations.

The interviewees working within elderly care were care workers or middle managers, most with an education in nursing or practical nursing. Practical nursing focuses on basic care, certain nursing tasks (for example, wound care and medication) and supporting the service users' functional capacity (bathing, dressing etc.) and autonomy in daily life, while nursing requires a higher education and involves a more extensive responsibility for medication, treatments and consultation of service users. The workplaces were female dominated and thus only two interviewees were men. The age of the interviewees varied from 24 to 64, the average age being 47. At Step-by-Step, eight of the interviewees were women and three were men. The age of the interviewees ranged from 25 to 60 , the majority being relatively young. The education of the interviewees varied from practical nursing and nursing to social work. The interviewees' work consisted of supporting the service users' rehabilitation mainly through participating in and instructing the service users in 
their everyday life. Two of the interviewees worked as superiors. However, they were also involved in practical care work.

\section{Analytical framework}

Building on a relational and performative ontological perspective, we conducted the analysis through an abductive research process. The analysis process was in other words iterative as we moved back a forth between theory and the data material. Our analysis consisted of four main phases, which we did not strictly follow in a linear way. Rather our process could best be described as taking a couple of step forward, only to return one step back, before proceeding again. In this process, we acknowledged the performativity of us as researchers in the practices of both collecting and analyzing the data.

The first phase involved developing an understanding of the studied phenomenon, as Barad (2007, p. 141) argues that "the primary ontological units are not "things" but phenomena - dynamic topological reconfigurations/entanglements/relationalities/(re)articulations of the world'. We therefore conducted readings and re-readings of the transcribed interviews to develop a preunderstanding of health promotion in the studied organizations. We knew that health promotion guided the care work in the studied organizations, so we were interested in understanding the material-discursive practices through which boundaries within the phenomenon were constituted. The coding began with a highlighting of all sections with reference to health promotion; both implicit and explicit references were included. In addition, we read organizational documents that we had gained access to. We focused on how the organizations framed their approach to care work. 
However, we decided not use direct citations from the documents in our reporting, in order to guarantee anonymity.

Having identified all sections of health promotion in the interviews, we proceeded to the second phase of the analysis. In this phase, we were concerned with an analysis of entanglements and intra-actions. Following a call for a 'focus on multiple types of materiality' (Putnam, 2015, p. 713) our analysis was relatively broad in the sense that we included entanglements of intra-acting (human and non-human) agencies, that is, bodies/spaces/objects-in-phenomena (Barad, 2007). We read the transcripts asking, how are bodies, spaces and objects entangled and intra-acting? How are subjects and objects positioned? As Ford et al. (2017, p. 1556), point out 'Barad's thesis cannot account for how subjects emerge in entangled intra-actions - Barad's human actor appears agentive but has no more consciousness than non-sentient actors'. To address this challenge we were inspired by Hultin and Introna (2019) and analyzed the interpellation of bodies or subjects into various subject or object positions, with a focus on how material-discursive health promoting practices conditioned possibilities for subjects and objects to act and be. However, we did not analyze subjects and objects as determined by the practices. Instead, we saw the relational performativity of health promotion as ever ongoing, never as fully constituted and always providing opportunity for transformation and resistance (Hultin and Introna, 2019). We used our notes of observations of spaces in this phase to deepen the analysis of the entanglements. This helped us to understand how spaces and objects were entangled with bodies.

In the third phase, we explored practices that emerged as legitimate in health promotion. We asked: What is enacted as legitimate? What is excluded? How is the excluded dealt with? We identified 
two material-discursive practices, which we coded as "confirming" and "balancing". Analyzing confirming and balancing helped us to understand the mundane practices of health promotion, how health promotion was enacted and structured the organizing of care work at EasyCare and Stepby-Step.

In the fourth phase, we combined the second and third phase. More specifically, we explored in detail how the entanglement of bodies/spaces/objects-in-phenomena were enacted in the practices of confirming and balancing. We then began to develop a performative theory of health promotion, showing how health promotion is accomplished in care work.

Table I summarizes the different phases of our analytical framework and includes illustrative examples of codes from the analyzed interviews (with words in bold to highlight out interpretation and coding of relevant themes).

INSERT TABLE I HERE

\section{Findings}

In both of the organizations studied, EasyCare and Step-by-Step, the aim of the care is defined as health promotion. More specifically, the organizations approach care from a rehabilitating perspective emphasizing predominantly the origins and causes of health in order to create and enhance different forms of health. EasyCare claims to specifically adopt a salutogenesis approach, 
which implies that the organization focuses primarily on factors that promote health, rather than on factors that may cause disease and decline. As one care worker said, her focus is on well-being and the older adults' strengths:

'The whole well-being of the person is in my thoughts all the time, this philosophy of EasyCare is exactly like my own: you see the individual as an individual and try to think of and build on her or his strengths and not just focus on her problems. '(Emma, EasyCare)

At a practical level this means that the aim at EasyCare is to enhance health and well-being by strengthening the older adults' functional capacity and by providing safe homes for older adults through an emphasis on the older adults' right of self-determination, respect and kindness in interpersonal relations.

Likewise, Step-by-Step defines its approach to care as 'recovery oriented practices', which means that the focus of care is on activities enhancing the service users' functional capacity instead of on diagnosis. At Step-by-Step, like at EasyCare, the service users and their situations are seen holistically emphasizing the whole human being as a starting point for care, instead of the illness. As one care worker explained:

'First of all, our starting point is the human, not the illness.' (Ron, Step-by-Step) 
As we hear above, the care worker highlights the importance of approaching service users' as 'humans' rather than focusing on illness. As illustrated in the quotes from Step-by-Step, the resident's needs and resources are described as the starting points for the rehabilitation and the health promoting processes. This is to enhance the resident's possibilities to influence her/his own life and to make changes that enable an as independent life as possible. The organizational objectives of EasyCare and Step-by-Step therefore provide suitable and fruitful contexts for examining health promotion in care services. In the following we will therefore analyze how health promotion is performed in ongoing practices in care work. First, we will contextualize the materialdiscursive health promoting practices. We then move on to exploring two types of practices: (1) confirming of health promotion and (2) balancing at the limits of health promotion, that is, practices of reconciling health promotion with that which does not neatly fit into it.

\section{Contextualizing material-discursive health promoting practices}

The spaces at EasyCare and Step-by-Step are designed to resemble 'normal' homes with a private bedroom for each service user and a shared kitchen as well as living room. The bedrooms can be decorated and furnished with the service users' own furniture, paintings, pictures, televisions, radios etc. in order for the service users to feel at home. The shared kitchen, dining room and living room are furnished by the organizations in cozy and quite non-institutional ways. The living rooms typically have two or several sofas enabling socializing, watching television, listening to music or reading the newspaper. In some homes, at EasyCare, you are often greeted by a dog when entering the care home, as some care workers bring their dogs to work and many service users enjoy the company of the dogs. In the interviews the care workers repeatedly emphasized 'this is a home': 
' Well, this is home. ....And we work in a home, and that is our starting point ... I always say that you can do your job, if you remember every morning that you come to someone's home, but if you think that they [the older adults] have moved into our workplace and disturb our job with question and so on, then something has gone wrong. ' (Pia, EasyCare)

\begin{abstract}
As Pia argues above, she sees EasyCare as a home and she emphasizes the importance of treating the workplace as such. As Markus, also claims, Step-by-Step is a long-term and safe home for many service users:

'Well, we have these people here, whose home this is. Most of them have lived here for 10 years. They have schizophrenia and have been ill for a long time. They have a more stable life here.' (Markus, Step-by-Step)
\end{abstract}

The daily life at Step-by-Step and EasyCare revolved to a large extent around typical homelike chores, such as, cooking, eating, showering, dressing and sleeping. Below a care worker from Stepby-Step describes the everyday mundane routines:

'A typical day builds on planned routines, which we follow. We have a weekly program and a daily program and we start the day by waking up the residents who need more support and then we have a morning meeting with them. In the meeting we go through different things for the day and week and 'keep people on track' and they get started with their chores. Then we have breakfast together. The residents 
help to make the breakfast and have a say in what we eat. Like in a normal home. And then they clean up with the cook and then we continue...' (Ron, Step-by-Step)

As Ron explains above, life at Step-by-Step revolves around creating as 'normal' everyday homelike routines as possible. Living at EasyCare's units also foremost involved particular homelike routines as described by Ella:

\begin{abstract}
'Well, this is a round-the-clock group home for persons with dementia. So my work tasks include all types of daily assistance depending on the resident: dressing, showering, sometimes helping with eating, preparing for different things, activities, going outdoors, pretty much everything. So, we have this homelike unit, we do everything together and also help people to maintain their functional capacity; that they participate as much as possible in things that have to be done every day. ' (Ella, EasyCare)
\end{abstract}

\begin{abstract}
Above we can hear how the daily routines involved choices regarding what to do, when to do certain daily activities and how to live in a homelike space. The spaces contributed to the establishment of the 'normal' home turning particular routines, such as, sleeping, eating, coking and showering into the most central and visible activities of the care. Ella reflected on the importance of these routines and that they are adapted to each service user's needs:
\end{abstract}


'We aim at being flexible to respect each and everyone's routines. ... for a person with dementia the routines are quite important, if you don't stick to them, it may sometimes cause chaos.' (Ella, EasyCare)

As Ella explains, flexible home-like routines adapted to the individual are important in the delivery of good care. The starting point at EasyCare is to maintain daily routines that the older adults have had before their arrival and to sustain health and slow down decline. The situation looks, however, somewhat different in the two organizations due to the different types of service users. At Stepby-Step many of the service users have, due to their illness and possible addiction, had difficulties with 'normal' everyday routines at their arrival. Therefore, the care work aims at enhancing the service users' ability to follow homelike routines to gain control and improve their health:

'... it's about having control over everyday life. We support them in those skills that may have disappeared due to the illness and bring them back again, improve them. Just normal everyday competencies from being tidy and cleaning to choosing a balanced diet. All that.' (Anne, Step-by-Step)

\begin{abstract}
The aim at Step-by-Step is thus, as explained by Ann, to teach, encourage and help the service users to carry out routines that promote a healthy body and life. Moreover, the focus at EasyCare and Step-by-Step is to help the service users to enhance or maintain their ability to carry out everyday tasks or to do them for the service users if they lack or have lost their ability to do them.
\end{abstract}


In addition, the care homes have offices for administrative task, such as, everyday documentation of care. The offices are typically rather small and within the care units. At EasyCare they are often next to the kitchen or living room, so that care workers can do administrative tasks in the end of the workday or when convenient, while further away at Step-by-Step. The service users can easily approach care workers conducting administrative tasks in both organizations. A care worker at EasyCare described the open-door policy in the organization:

'We have no closed doors here. Instead we have windows [to the office] and an open door. So many of them [the older adults] appraoch me, usually just to have a chat.' (Julia, EasyCare)

As we hear here, the open-door policy to the offices meant that it was easy for the older adults to approach the care workers when they were doing administrative tasks. At EasyCare, typically, daily administrative tasks are done in the office, but it is possible to do tasks, for example, on the balcony or in the shared living room. Tasks that require an input from the service users are done in the shared area or more privately in the bedrooms.

\begin{abstract}
Above, we have illustrated the material-discursive sites and what the everyday care routines look like at EasyCare and Step-by-Step. Let us now turn to examining how health promotion is accomplish through particular entanglements of meaning and materiality in this context through confirming health promotion or through balancing at the limits of health promotion.
\end{abstract}

\title{
Confirming health promotion
}


While there are several possible ways of how health promotion can be performatively constituted, the interviewees strongly expressed confirming of health promotion through particular subject positioning of the service users as we will illustrate below. More specifically, the care workers referred relatively consistently to service users as 'resident' (occasionally senior or elderly were used at EasyCare and person undergoing rehabilitation at Step-by-Step). The service users were in other words primarily subject positioned as persons leading ordinary everyday life at home (although in need of more or less round-the-clock care). In this, materialities, such as, bodies (of the ill/healthy service users and care workers), and the home as spaces/objects were entangled with discourse. Typically, the care workers described the service users or the 'residents' as individuals. For example, a care worker at Step-by-Step explained that the service user is always approached as unique individual:

'They are always treated as individuals and we look at each person's condition individually.' (Benjamin, Step-by-Step)

As above, care workers at EasyCare also emphasized the importance of recognizing the service user's unique past, interests and life story, and use these as a foundation in the health promoting care work:

'Our aim is to take their past and their interests into consideration. We use their life story as a foundation here so that we consider what this person still can do, what she has been able to do and has enjoyed. That's important.' (Emma, EasyCare) 
As we hear above the resident is subject positioned as a unique individual: as a person with particular material needs and with a life story. This is used as a central foundation and starting point in care practices. In addition, seeing the resident as unique also meant subject positioning the resident as 'unfixed' in the sense that she or he may have changing preferences and habits. As Lisa explained, care workers must always be alert for changing preferences:

'If the person has had porridge with blueberry soup every morning for 1,5 years I still ask: "What would you like to have today?" and give some options, because she might just actually want something different today.' (Lisa, EasyCare)

\begin{abstract}
Here, as in many interviews, the care worker emphasizes the importance of giving choice and thus the residents is subject positioned as 'unfixed', as a subject always potentially open for change and transformation in everyday life. Thus, the care workers promoting health must constantly be sensitive for and provide option for change and alternatives.
\end{abstract}

\begin{abstract}
If we return to the cozy homelike spaces described previously, we can begin to see how this particular resident subject position (the service user as an individual and as unfixed) was reproduced by the care workers in practices. More specifically, the care workers typically talked about themselves as skillful helpers and enablers, who continuously, in their encounters with the service users, sense and respond to the 'residents' needs. For example, as a care workers at Stepby-Step explained, care workers must recognize at the arrival of a new service user her/his needs in order to provide rehabilitation:
\end{abstract}


'They may come straight from the hospital in a poor condition and it's crucial how you pick up the persons issues and start the rehabilitation and everything. You just have to figure it out, that it's not the same, not to act the same way with everyone.' (Katarina, Step-by-Step)

\begin{abstract}
As Katarina explains, care workers must identify the service users individual needs and use that knowledge in the health promoting care. Likewise care workers at EasyCare highlighted their positions as enablers of the older adults' different needs in the daily routines. One care worker, Lisa, explained:

'It is in my and hers or his best interest, that I have found out how they want to spend their time, what's important and then I come in when needed and help with the morning routines, with eating or anything, if they want to go for a walk. Yeah, these normal things that everyone does. And if there's something they can't do or don't have the strength to do I come in as a support, but you have to make sure that you don't do things they can do on their own.' (Lisa, EasyCare)
\end{abstract}

Here we can discern the becoming of health promotion; how health promotion is performed in practice, when care workers enable service users everyday routines and life. Moreover, we see how health promotion is accomplished through a confirming and enabling of 'the resident' and 'the home'; they emerge through entangled intra-actions. Simultaneously the care workers are subject positioned as enablers of the health promotion (the home and the resident). Health 
promotion emerges, in other words, through the entanglement of matter and meaning of different bodies, illness, health, and homelike spaces and objects, in practice.

In sum, health promotion is accomplished through particular ongoing material-discursive practices of confirming at EasyCare and Step-by-Step. The everyday confirming through subject positioning and object positioning draws attention to that which becomes legitimate. Our analysis so far has shed light on the material-discursive production of the boundaries of bodies, spaces and objects and by doing so demonstrated the emergence of 'the resident' in 'the home' as legitimate in health promoting care work. This shapes the appropriate ways of being and acting at EasyCare and Stepby-Step. More specifically, a strong confirming of health promotion was a, or perhaps even the most, central material-discursive practice of the care work: by confirming, health promotion became a powerful way of organizing care. In that sense the confirming structured processes through which EasyCare and Step-by-Step are constituted over time.

\section{Balancing on the limits of health promotion}

While the material-discursive practices of confirming structure how the health promoting care is constituted at EasyCare and Step-by-Step, the practices simultaneously constitute exclusions. In the everyday work practices care workers are faced with both that which is promoted and/or legitimate, and that which is not. Although the care workers typically confirm health promotion, our analysis shows glimpses of situations that reveal how confirming is not always possible. In these situations, the care work at times involves discomfort or reflection amongst care workers, which we understand as acts of balancing at the limits of health promotion. By engaging in balancing the care workers seek to reconcile tensions that emerge between health promotion and 
other practices. In this section we will therefore proceed to examine care workers' discomfort and reflections about tensions in the production of 'the resident' and 'the home'. Let us first examine some accounts that include primarily 'the residents' and balancing.

While care is primarily performed at Step-by-Step and EasyCare through practices of health promotion, it is important to highlight that most service users have serious illnesses and/or chronic diseases. In the following quote a care worker from Step-by-Step note the poor condition of (some of) the service users:

\author{
'Well, we have a few who are in such a poor condition; some are of course constantly \\ slightly psychotic.' (Hannele, Step-by-Step)
}

\begin{abstract}
Above Hannele describes the serious illnesses of many service users. Likewise, Erik at EasyCare talks about how older adults often today are in a worse condition than in the past when moving into a care home:

'The care today [in society] aims to keep everyone [older adults] at home for as long as possible. When they finally are admitted to a care home, they are in a poor condition.' (Erik, EasyCare)
\end{abstract}

\begin{abstract}
As Erik points out above, a shift in care ideologies in Finland, away from care in institutions towards providing care at home has implied that currently services users increasingly have more serious illnesses when admitted to the care homes. However, despite the serious illnesses, the
\end{abstract}


service users were subject positioned as residents while alternative or contradicting service user subject positions were resisted, but still used at times. One such instance was, as shown in the extract below, when a care worker, Susanne, thought of service users as patients. She then corrected herself according to the preferred term, resident:

\author{
'Well, I find it difficult, I call them patients, but they are not patients here, they are \\ residents.' (Susanne, EasyCare)
}

\begin{abstract}
Above we can hear how Susanne corrects her subject positioning of service users. This could be interpreted as a form of confirming, but it can been also seen as an act of balancing. The balancing is grounded in the health promotion that guides the care work towards approaching service users as residents thus drawing attention to health rather than illness. Although the care workers embrace this approach to care work, the balancing reveals how they also see the patient (or illness) in the service users, but correct themselves to conform with health promotion to produce particular legitimate distinctions of bodies, spaces and objects. Thus, it could be argued that the acts of balancing show how health promotion contributes to what is emphasized in care (for example, health rather than illness) and what is left in the margins.
\end{abstract}

However, it must be emphasized, that there were also moments in the interviews in which the service user was subject positioned, for example, as a patient, without discomfort. Such moments were when care workers used certain objects (medication and medical devices, for example, lifts and blood-pressure gauges) or when illness was strongly present (for example, psychosis and during terminal care). For example, a care worker from Step-by-Step referred without discomfort 
to service users as 'human beings' and 'persons' with illnesses, in contrast to understanding the service users as a residents with health promoting strengths.

Material realities, such as, illness and decline did, however, often not fit well with the everyday health promotion practices. When, for example, a service user becomes severely ill or shows signs of chronic illness, health promotion can become limiting. One care worker at EasyCare expressed discomfort when talking about having to provide care that does not primarily build on health promotion:

'... when they [the older adults] slowly get weaker, it is hard to let go and to accept that “well, today she doesn't have the strength, well then she has to rest", it's really difficult to let go...' (Rebecca, EasyCare)

Here Rebecca describes her experiences of discomfort when the ill body of a service user hinder her from supporting the service users in what are seen as normal daily chores and practices and instead she has to let the service user rest. In a similar vein, Katarina from Step-by-Step talks about the experiences of accepting that a service user's care aims cannot always be meet:

'Sometimes you have to put yourself out there and put up with that things don't go as you wish.' (Katarina, Step-by-Step)

Both Rebecca's and Katarina's accounts above make the limits of health promotion discernible through their acts of balancing. The care workers' acts of balancing emerge through the difficulty 
of escaping the fact that the residents' bodies are entangled not only with health, but also with illness. In these cases, care workers are pushed into arenas where they are forced to carry out and organize their work based on other principles than the ones provided by health promotion.

Another act of balancing involved reconciling care for (chronically) ill with health promotion by adjusting the care and care aims. For example, Markus at Step-by-Step argued that not all service user may recover to the extent that she or he can join the labor market:

'... although they [the residents] have a good social life and attend courses, and don't end up in the hospital, have a good life and participate, for example, in one of these rehabilitating activities; this is for many an achievement that is as good as a paid job.' (Markus, Step-by-Step)

\begin{abstract}
As Markus explains above, not all service users may recover from their drug addiction or mental illness to the extent that they could join the labor market. However, other achievements, such as, studies are considered as a sign of successful rehabilitation. Similarly, Hanna at EasyCare, talks about adjusting health promoting activities to better suit the service users conditions:
\end{abstract}

'It has been a long process for me, too, that it's ok to just have a cup of coffee. It can be equally valuable as going to the fish market we them... the small but valuable moments [for example, a nice cup of coffee with the service user] in the everyday practices are important.' (Hanna, EasyCare) 
As Hanna says, after long process she has come to realize that health promoting care does not always require organized activities or excursions, as they may have negative effects on or be stressful for older adults, while a nice chat over a cup of coffee may be more health promoting. What we can see here are adjustments that depart from certain health promotion aims: the care worker discusses how the care work may not result in or involve the ultimate goal of care when illness requires alternative practices and/or care aims. These acts of balancing hence illustrate how ill bodies and their limitations are reconciled with health promotion.

We now turn to examining how that which does not fit neatly with health promotion is reconciled in 'the home'. One care worker, Lisa, claimed that accomplishing 'the home' is a continuous struggle:

\author{
'We have to fight it all the time ... we mustn't encounter those who live at EasyCare \\ as this was a hospital, which we definitely aren't. That's why we refuse to talk about \\ units. Here we are in somebody's home, we always knock on the door before we enter \\ regardless how well we know each other.' (Lisa, EasyCare)
}

\begin{abstract}
Here Lisa explains how accomplishing the home involves acts of balancing through distancing from that which typically is distinctive for hospitals. Balancing in daily practices is here about how the organization is talked about (as a home, not as units), how to act in the home, and how to encounter and subject position service users as residents.
\end{abstract}


While we can see that illness and the institution were at times in tension with health promotion (that is, 'the resident' and 'the home') another, perhaps, even bigger challenge, was certain tensions between organizing including administration and health promotion at EasyCare. More specifically, balancing at EasyCare at times involved concealing some aspects of organizing from 'the residents'. While many spaces and objects typical for homes fitted well into 'the home', spaces and objects connected to the institution and control produce at times balancing, as they were difficult to align neatly into health promotion. A concern for many care workers at EasyCare was that the care homes, in particular modern ones, often are designed specifically as homes and therefore lack suitable office spaces, as Christina explained:

'It's really a problem, there's no quite corner where you can think without disruptions.' (Christina, EasyCare)

\begin{abstract}
Another related challenge was that the care homes had increasingly began using computers for administrative task. Introducing computers changed the way documentation often was done. Megan explained how many care workers felt uncomfortable documenting care on laptops next to the service users and thus they avoided doing it:
\end{abstract}

'Now they just sit in the office [the care workers doing administrative tasks], before they used to take the paper folders and sit down among the older adults, but to sit and write on the laptop, doesn't quite work.' (Megan, EasyCare) 
As the care worker explains documentation has increasing moved into the small offices at EasyCare as care workers were not comfortable using laptops in the service users' living rooms. Many care workers felt that documenting care on laptops next to older adults did not respect 'the resident' and thus did not have an unproblematic place in 'the home'. As Hanna said, the practice of writing documentation reports, is not always clear for service users with illnesses, such as, dementia:

'... I could never say to them [the older adults] that "I will go and write a report regarding you", as I work with persons with dementia. They would say: "What? About me? What's wrong with me?". They don't see themselves as ill, they know they live here, they know that they have lost parts of their health... they think EasyCare is super and they love it here, sometimes they can even think that they are staying at a hotel. That's why they wouldn't like someone to write a report about them. They are here voluntarily, they're not here because they have to, that's why we don't write reports [legally required documentation] in their presence. That would be offensive.' (Hanna, EasyCare)

\footnotetext{
As we can hear here, care workers often have to engage in balancing to accomplish health promotion. Both the computer and the act of documenting are typically not seen as something to be shown to the service users. Balancing thus becomes an act of partly confirming and upholding health promotion practices in order to maintain the resident or the healthy body and consequently the home, while simultaneously partly acknowledging the institution and ensuring that it is only enacted behind the scenes in small offices.
} 
To conclude, the acts of balancing highlight important limits of health promoting care work. Balancing occurs in and through the intra-action of bodies, spaces and object and illuminates how 'ill patients' or 'declining bodies', office spaces and particular organizational objects (foremost computers) are in tension with health promotion. Our analysis shows how care workers seek to reconcile these tensions. More specifically, despite experiences of discomfort, the care workers often reject the subject positioning of service users as patients, they fight against an institutionalization of the home, adjust care aims and hide to a certain extent administration and organizing.

\section{Discussion}

As health promotion has gained increasing attention in organizations, politics, policy and care during the last decade (Bache and Reardon, 2016; Cederstöm and Spicer, 2015; Dale and Burrell, 2014) we have examined this phenomenon in a context rarely explored in organization studies: care work focused on health promotion in a context of illness and/or decline. More specifically, we have explored the phenomenon of health promotion from a performative perspective with a focus on material-discursive practices. Previous organization studies have to some extent explored health promotion and care work, but typically separately, although this type of work is particularly entangled with issues of health and recovery. Further, the few studies that have adopted a performative approach to material-discursive practices in studies of care and health organizations have typically focused primarily on IT, while we have approached care work more broadly around bodies, spaces and objects without prioritizing IT use or implementation as a starting point of the analysis. We have therefore explored health promotion in a context where health, illness and decline are at the heart of the organizational activities and thus extend previous literature by 
producing new insights: (1) from an important context of health promotion and (2) of underresearched entanglements of human and non-human actors beyond IT.

By adopting a material-discursive approach this study offers a performative theory of reconciling organizational tensions. More specifically, we have examined health promotion as relational, performative and entangled material-discursive practices (Barad, 2003; 2007; Orlikowski and Scott, 2015). Our approach is relational as we understand health promotion, not as a self-contained social or material entity of care work, but as acquiring properties through entanglements in ongoing processes of becoming (Scott and Orlikowski, 2014). Thus we have focused on health promotion as relationality within care work and examined and theorized health promotion as entanglements of meaning and materiality that emerge through ongoing material-discursive practices. By analyzing material-discursive practices as arenas for performativity, actions and doings, we have seen how health promotion is configured in mundane care work and is a boundary making activity. Material-discursive practices are in other words practices of both particular inclusions and exclusions. In our study, we have identified two central practices: (1) the confirming of health promotion and (2) the balancing on the limits of health promotion. These practices enact specific distinctions and boundaries of the studied phenomenon, which Barad (2003) calls agential cuts. Agential cuts are therefore not inherent distinctions, but ongoingly performed. Let us take a closer look below at the agential cuts and their implications as enacted at EasyCare and Step-by-Step.

The confirming, a critical ongoing material-discursive practice at EasyCare and Step-by-Step, enacted health promotion through particular subject and object positionings (Hultin and Introna, 2019). Here material-discursive bodies, spaces and objects constituted agential cuts through which 
the service users were positioned as 'residents' and the organizations as 'homes'. 'The resident' and 'the home' were in other words important agential cuts in the enactment of health promotion and configured care work in critical ways, making organizational practices primarily about 'normal' homelike activities governing subject and object positioning.

Practices of balancing made the boundaries and limitations of the agential cuts discernible and attempted to reconcile that which had been legitimized by confirming enactments with that which did not fit neatly with health promotion. The acts of balancing were thus attempts to find appropriate ways of being and acting with illness, unachievable care aims, the institution and organizing within health promotion. Said differently, material-discursive entanglements and intraaction of bodies, spaces and objects constituted the tensions, but simultaneously also produced reconciliation.

From the above follows that our study has highlighted how discrepancies between health promotion and certain mundane care practices emerge and constitute each other. Therefore, our performative theory of reconciling organizational tensions claims that balancing within the discrepancies is entangled with the becoming of health promotion. In this process of becoming confirming and balancing condition the possibilities and agency for subjects and objects in care work (Hultin and Introna, 2019). As Barad (2007, p. 235), argues, 'agency is a matter of intraacting'; neither humans nor non-humans are determined or pre-exist, but emerge within a phenomenon. Or like Hultin and Mähring (2017, p. 586) explain, agency does not belong to any one actor, but 'flow through material-discursive practices' and 'certain actions condition the possibilities for other actions'. At EasyCare and Step-by-Step the organizational actions 
conditioned foremost possibilities to confirm health promotion. Although the acts of balancing reveal that confirming is not always possible, the care workers embraced it as a good way of organizing care. Rather than resisting health promotion the care workers strived to find ways to reconcile material-discursive tensions within health promotion. Hence, both the acts of confirming and balancing show how the celebration of the resident is central in the production of a relatively unquestioning health promotion approach to care in the organizations studied.

The lack of problematizations of health promotion is perhaps not surprising as the organizing of care is essentially about caring for ill and/or aging bodies, but there are numerous examples of how, for example, cost-efficient practices and profit seeking primarily structure care. Therefore, confirming and balancing are important for the theorizing of the enactment of possibility, that is, how health promotion can act as a powerful structuring process in organizations (Scott and Orlikowski, 2014).

\section{Conclusions}

In this article, we have examined how care workers in care organizations accomplish health promotion. More specifically, we have analyzed material-discursive and performative aspects of health promotion. We have identified two central material-discursive health promoting practices in care work: confirming that celebrates service users as residents and the organizations as a home, and balancing at the limits of health promotion. Our performative theory of reconciling organizational tensions argues that balancing is entangled with the becoming of health promotion, 
and that confirming and balancing condition the possibilities for subjects and objects in care work in particular ways.

More specifically, our theorizing shows how health promotion can structure processes in care homes where illness and decline often are particularly palpable. However, health is always entangled with its necessary Other, illness (Dale and Burrell, 2014). Therefore, in our analysis we were struck by the absence of questioning health promotion. The absence of questioning may suggest that there is a need for critical readings and problematizations of health promotion. On the other hand, the relatively strong confirming of health promotion may be a result of care organizations' commitment to work ethics that take health as a starting point turning health promotion to a service user oriented approach, rather than building on a narrow focus on productivity, cost-efficiency or medicalization. While this health promoting approach has numerous benefits, such as, service user satisfaction and a resistance towards harmful subject positioning (Crossley, 2000), it is also apparent that the enactment of health promotion is at times experienced as problematic and ambivalent by some care workers. However, the salutogenesis approach emphasizes that health promotion and prevention of disease can be seen as two sides of the same coin (Eriksson and Lindström, 2006; Chrysikou et al., 2018), suggesting that care organization could gain from carefully approaching care as an entanglement of practices of salutogenesis and pathogenesis. Our study and theorizing therefore stresses the need to pay more attention to how the limits of health promotion can become less ambivalent, in order to improve quality in care and to support care workers who often work under pressure. This may enhance care worker well-being and satisfaction in a context where employee turnover, professional exit and burnouts are not rare (Woo et al., 2020). In addition, we wish to point out that the increasing 
deinstitutionalization of care in many national contexts and the increasing number of service users with more serious illnesses in care homes suggests that it is ever more important to consider how health promotion is enacted in care organizations.

Our study foremost contributes to qualitative research in organizations and management and advances material-discursive performative approaches. Studies examining material-discursive practices in the context of health and care organizations have typically primarily focused on the use and implementation of IT (Gond et al., 2016). By their primary focus on various aspects around IT and technologies, these studies have paid less attention to other types of human and non-human actors central to care organizations. We have extended this literature by theorizing how health, illness and decline condition and are conditioned by core (often health promoting) organizational activities. More broadly and in accordance with Barad's understanding of material-discursive practices we have theorized the intra-action of different types of entangled and ever-becoming human and non-human actors through which organizational realities come into being. More specifically, we have theorized how the reconciliation of organizational tensions and paradoxes can be performed in organizations and potentially beyond.

As any study, ours also has certain limitations. We have examined health promotion in a context of strong acts of confirming and some balancing. We have not, however, engaged in theorizing resistance beyond balancing in health promoting care work, as our empirical data did not provide fruitful grounds for this. We therefore argue that it is of importance that future organizational studies examine and theorize how resistance is performed and enacted in health promoting care 
work. Lastly, while our study focused on the enactment of health promotion as described by the care workers, it would be equally important to study how this is done by the service users.

\section{References}

Antonovsky, A. (1979), Health, stress and coping, the Jossey-Bass Social and Behavioural Science Series, San Francisco.

Ashcraft, K. L., Kuhn, T. R. and Cooren, F. (2009), “Constitutional Amendments: Materializing Organizational Communication", The Academy of Management Annals, Vol. 3 No. 1, pp.164.

Bache, I. and Reardon, L. (2016), The Politics and Policy of Wellbeing: Understanding the Rise and Significance of a New Agenda, Edward Elgar Publishing, Cheltenham, UK.

Barad, K. (2007), Meeting the universe halfway, Duke University Press, Durham.

Barad, K. (2003), "Posthumanist Performativity: Toward an Understanding of How Matter Comes to Matter", Signs: Journal of Women in Culture and Society, Vol. 28 No. 3, pp.801-831.

Becker, C. M., Glascoff, M. A., Felts, W. M. and Kent, C. (2015), “Adapting and using quality management methods to improve health promotion", EXPLORE, Vol. 11 No. 3, pp.222-228.

Becker, C. M. and Rhynders, P. (2013), "It's time to make the profession of health about health", Scandinavian journal of public health, Vol. 41 No. 1, pp.1-3.

Cederström, C. and Spicer, A. (2015), The Wellness Syndrome, Polity Press, Cambridge, UK.

Chamberlain, K. and Murray, M. (2009), "Critical health psychology”, Fox, D., Prilleltensky, I. and Austin S. (Ed.), Critical Psychology: An Introduction, 2nd ed., Sage, London, England, pp.144-158. 
Chrysikou, E., Tziraki, C. and Buhalis, D. (2018), “Architectural hybrids for living across the lifespan: lessons from dementia”, The Service Industries Journal, Vol. 38 No. 1-2, pp.4-26.

Cohen, R. L. and Wolkowitz, C. (2018), "The feminization of body work", Gender, Work and Organization, Vol. 25 No. 1, pp.42-62.

Crossley, M. (2000), Rethinking Health Psychology, Open University Press, Buckingham, Philadelphia.

Dale, K. (2005), "Building a social materiality: Spatial and embodied politics in organizational control”, Organization, Vol. 12 No. 5, pp. 649-678.

Dale, K. and Burrell, G. (2014), "Being occupied: An embodied re-reading of organizational 'wellness'”, Organization, Vol. 21 No. 2, pp.159-177.

Deetz, S. (2003), "Reclaiming the legacy of the linguistic turn", Organization, Vol. 10 No. 3, pp.421-429.

Eriksson, M. and Lindström, B. (2006), “Antonovsky's sense of coherence scale and the relation with health: a systematic review", Journal of epidemiology and community health, Vol. 60 No. 5, pp.376-381.

Fineman, S. (2014), “Age matters”, Organization Studies, Vol. 35 No. 11, pp.1719-1723.

Ford, J., Harding, N. H., Gilmore, S., and Richardson, S. (2017), "Becoming the leader: Leadership as material presence”, Organization Studies, Vol 38 No. 11, pp.1553-1571.

Fotaki, M., Metcalfe, B. D. and Harding, N. (2014), "Writing materiality into management and organization studies through and with Luce Irigaray”, Human Relations, Vol. 67 No. 10, pp.1239-1263. 
Gherardi, S., Meriläinen, S., Strati, A. and Valtonen, A. (2013), “Editors' introduction: A practicebased view on the body, senses and knowing in organization", Scandinavian Journal of Management, Vol. 4 No. 29, pp.333-337.

Gherardi, S., and Rodeschini, G. (2016), "Caring as a collective knowledgeable doing: About concern and being concerned", Management Learning, Vol 47 No. 3, 266-284.

Gond, J. P., Cabantous, L., Harding, N. and Learmonth, M. (2016), "What do we mean by performativity in organizational and management theory? The uses and abuses of performativity”, International Journal of Management Reviews, Vol. 18 No. 4, pp.440-463.

Harding, N. H., Ford, J. and Lee, H. (2017), Towards a performative theory of resistance: Senior managers and revolting subject(ivitie)s”, Organization Studies, Vol. 38 No. 9, pp.1209-1232.

Hardy, C. and Thomas, R. (2015), "Discourse in a material world", Journal of Management Studies, Vol. 52 No. 5, pp.680-696.

Hearn, J. (2014), "Men, masculinities and the material (-) discursive", NORMA: International Journal for Masculinity Studies, Vol. 9 No. 1, pp.5-17.

Holmqvist, M. (2009), "Corporate social responsibility as corporate social control: The case of work-site health promotion", Scandinavian Journal of Management, Vol. 25 No. 1, pp.68-72.

Hultin, L. and Introna, L. (2019), “On Receiving Asylum Seekers: Identity working as a process of material-discursive interpellation”, Organization Studies, Vol. 40 No. 9, pp.1361-1386.

Hultin, L. and Mähring, M. (2017), "How practice makes sense in healthcare operations: Studying sensemaking as performative, material-discursive practice", Human Relations, Vol. 70 No. 5, pp.566-593. 
Introna, L. D., Hayes, N., and Al-Hejin, Z. (2019), “The negotiated order and electronic patient records: A sociomaterial perspective”, Journal of Information Technology, Vol 34 No. 4, pp.333-349.

James, E. P. and Zoller, H. M. (2018), "Resistance training:(Re) shaping extreme forms of workplace health promotion”, Management Communication Quarterly, Vol. 32 No. 1, pp.6089.

Jensen, M. C. F., and Muhr, S. L. (2020), "Performative identity regulation in rehabilitative home care work: an analysis of how experts' embodied mediation of the managerial ideology 'activates' new frontline identities”, Culture and Organization, Vol 26 No. 3, pp.211-230.

Jones, M. (2014), “A matter of life and death: Exploring conceptualizations of sociomateriality in the context of critical care", MIS Quarterly, Vol. 38 No. 3, pp.895-925.

Jones, L. and Watson, B. (2009), “Complex Health Communication: A Language and Social Psychological Perspective”, Journal of Language and Social Psychology, Vol. 28 No. 2, pp.115-118.

Lindberg, K. (2014), "Performing multiple logics in practice", Scandinavian Journal of Management, Vol. 30 No. 4, pp.485-497.

Lupton, D. (1995), The imperative of health: Public health and the regulated body, Sage, London, England.

Maravelias, C. (2009), "Health promotion and flexibility: Extending and obscuring power in organizations", British Journal of Management, Vol. 20, pp.194-203.

McKinlay, A. and McVittie, C. (2009), Social Psychology and Discourse, Wiley-Blackwell, Chichester, UK. 
Meldgaard Hansen, A. and Kamp, A. (2018), "From carers to trainers: professional identity and body work in rehabilitative eldercare", Gender, Work and Organization, Vol. 25 No. 1, pp.6376.

Munro, I. and Randall, J. (2007), “I Don't Know What I'm Doing, How About You?': Discourse and Identity in Practitioners Dealing with the Survivors of Childhood Sexual Abuse", Organization, Vol. 14 No. 6, pp.887-907.

Nielsen, K. (2013), "How can we make organizational interventions work? Employees and line managers as actively crafting interventions", Human Relations, Vol. 66 No. 8, pp.1029-1050.

Nyström, M. E., Höög, E., Garvare, R., Weinehall, L. and Ivarsson, A. (2013), “Change and learning strategies in large scale change programs", Journal of Organizational Change Management, Vol. 26 No 6, pp.1020-1044.

Orlikowski, W. J. and Scott, S. V. (2015), "Exploring material-discursive practices”, Journal of Management Studies, Vol. 52 No. 5, pp.697-705.

Phillips, N. and Oswick, C. (2012), "Organizational discourse: Domains, debates, and directions", The Academy of Management Annals, Vol. 6 No. 1, pp.435-481.

Polykarpou, S., Barrett, M., Oborn, E., Salge, T. O., Antons, D., and Kohli, R. (2018), “Justifying health IT investments: A process model of framing practices and reputational value", Information and Organization, Vol. 28 No. 4, pp. 153-169.

Putnam, L. L. (2015), "Unpacking the dialectic: Alternative views on the discourse-materiality relationship", Journal of Management Studies, Vol. 52 No. 5, pp.706-716.

Scott, S. V. and Orlikowski, W. J. (2014), "Entanglements in Practice”, Mis Quarterly, Vol. 38 No. 3, pp.873-894. 
Thanem, T. (2013), "More passion than the job requires? Monstrously transgressive leadership in the promotion of health at work", Leadership, Vol. 9 No. 3, pp.396-415.

Thanem, T. (2009), "There's no limit to how much you can consume’: the New Public Health and the struggle to manage healthy bodies", Culture and organization, Vol. 15 No. 1, pp.59-74.

Timmons, S., Vezyridis, P., and Sahota, O. (2019), "Trialling technologies to reduce hospital in-patient falls: an agential realist analysis", Sociology of health \& illness, Vol 41 No. 6, 11041119.

Torrès, O. and Thurik, R. (2019), "Small business owners and health”, Small Business Economics, Vol. 53 No. 2, pp.311-321.

Woo, T., Ho, R., Tang, A. and Tam, W. (2020), "Global prevalence of burnout symptoms among nurses: A systematic review and meta-analysis", Journal of Psychiatric Research, Vol. 123, pp.9-20.

Yakhlef, A. and Essén, A. (2013), "Practice innovation as bodily skills: The example of elderly home care service delivery”, Organization, Vol. 20 No. 6, pp.881-903. 
Table I. Codes of analysis and illustrative interview quotes.

\begin{tabular}{|c|c|c|}
\hline Phase & Focus of coding & Examples from the interview material \\
\hline 1 & $\begin{array}{l}\text { References to health } \\
\text { promotion }\end{array}$ & $\begin{array}{l}\text { 'The whole well-being of the person is in my thoughts all } \\
\text { the time, this philosophy of EasyCare is exactly like my } \\
\text { own: you see the individual as an individual and try to } \\
\text { think of and build on her or his strengths and not just } \\
\text { focus on her problems.' }\end{array}$ \\
\hline 2 & $\begin{array}{l}\text { Intra-actions of human } \\
\text { and non-human agencies } \\
\text { (bodies, spaces and } \\
\text { objects) }\end{array}$ & $\begin{array}{l}\text { 'Well, we have these people here, whose home this is. } \\
\text { Most of them have lived here for } 10 \text { years. They have } \\
\text { schizophrenia and have been ill for a long time. They have } \\
\text { a more stable life here.' }\end{array}$ \\
\hline 3 & $\begin{array}{l}\text { Material-discursive } \\
\text { practices (two identified } \\
\text { and named as confirming } \\
\text { and balancing) }\end{array}$ & $\begin{array}{l}\text { Confirming: 'Our aim is to take their past and their } \\
\text { interests into consideration. We use their life story as a } \\
\text { foundation here so that we consider what this person still } \\
\text { can do, what she has been able to do and has enjoyed. } \\
\text { That's important.' } \\
\text { Balancing: 'Well, I find it difficult, I call them patients, } \\
\text { but they are not patients here, they are residents.' }\end{array}$ \\
\hline 4 & $\begin{array}{l}\text { Intra-actions between } \\
\text { human and non-human } \\
\text { agencies in the material- } \\
\text { discursive practices } \\
\text { (intra-actions of bodies, } \\
\text { spaces and objects within } \\
\text { confirming and } \\
\text { balancing) }\end{array}$ & $\begin{array}{l}\text { Confirming: 'We aim at being flexible to respect each and } \\
\text { everyone's routines. ... for a person with dementia the } \\
\text { routines are quite important, if you don't stick to them, it } \\
\text { may sometimes cause chaos.' } \\
\text { Balancing: '... when they [the older adults] slowly get } \\
\text { weaker, it is hard to let go and to accept that "well, today } \\
\text { she doesn't have the strength, well then she has to rest", } \\
\text { it's really difficult to let go...' }\end{array}$ \\
\hline
\end{tabular}

